\title{
Radioluminescent, thermoluminescent and dosimetric properties of X-ray phosphors
}

\author{
M. Ignatovych ${ }^{(1)}$, A. Kelemen ${ }^{(2)}$, N. Otvas ${ }^{(2)}$, A. Peto ${ }^{(2)}$ and V. Ogenko ${ }^{(1)}$ \\ (1) Institute for Surface Chemistry of National Academy of Sciences of Ukraine, 31 Prospect Nauky, Kyiv, 252028, Ukraine. \\ FAX: 380-44-264 04-46 \\ (2) Institute for Isotope and Surface Chemistry, Hungarian Academy of Sciences, Budapest P. O. Box 77, 1525, Hungary. \\ FAX:36-1-395-9002
}

\begin{abstract}
Time-resolved radioluminescence (RL) of X-ray phosphors: BaFCl:Eu, ZnS.CdS:Ag and $\mathrm{Y}_{2} \mathrm{O}_{3}: \mathrm{Eu}$, which exhibited ultraviolet $\left(\lambda_{\max }=390 \mathrm{~nm}\right)$, yellow-green, $\left(\lambda_{\max }=530 \mathrm{~nm}\right)$ and red $\left(\lambda_{\max }=620 \mathrm{~nm}\right)$ luminescence respectively, have been measured. For tested phosphors a good proportionality between the light output of the radioluminescence and the dose rate in the region of dose rates from 3 to $45 \mathrm{MGy} / \mathrm{s}$ has been obtained. It was also revealed that the emitting properties of all phosphors are preserved after high-dose $\left(10^{4} \mathrm{~Gy}\right)$ and high temperature $\left(500^{\circ} \mathrm{C}\right)$ annealing the samples. Thermoluminescent (TL) characterization of $\mathrm{Sr}_{3}\left(\mathrm{PO}_{4}\right)_{2}: \mathrm{Eu}$ and $\mathrm{BaFCl}: \mathrm{Eu}$ under X-ray, beta and gamma irradiation have been performed. Linear TL dose dependence under irradiation dose in the mGy - Gy region was revealed, which makes these phosphors suitable also for luminescence dosimetry in the low doses region. Thus, the main characteristics of phosphors: i) the high conversion efficiency, ii) the good dose-rate proportionality, iii) the radiation stability allow to consider these materials as promising for high-energy and high dose rate dosimetry.
\end{abstract}

Keywords: X-ray phosphor, radioluminescence, thermoluminescence, dosimetry.

Paper received 12.10.99; revised manuscript received 04.01.00; accepted for publication 21.03.00.

\section{Introduction}

The study is devoted to visualization and detection of high-level, high-energy and high dose rate ionizing radiation created by isotopes of Chernobyl accident, that are still present inside Chernobyl Shelter. Our approach in solving the problem of visualization was to apply the $\mathrm{X}$-ray phosphors widely used for intensifying luminescent screens or in computed tomography $[1,2]$ and to test their emitting properties under high-energy and high-dose conditions.

Here we report on spectral (RL, TL) and dosimetric properties of X-ray phosphors, which displayed high efficiency in converting the ionizing radiation into visible luminescence $[3,4]$.

\section{Experimental}

Materials: Samples of Eu-containing phosphors such as $\mathrm{BaFCl}: \mathrm{Eu}, \mathrm{Sr}_{3}\left(\mathrm{PO}_{4}\right)_{2}: \mathrm{Eu}, \mathrm{Y}_{2} \mathrm{O}_{3}: \mathrm{Eu}$ and $\mathrm{ZnS} . \mathrm{CdS}: \mathrm{Ag}$ have been studied. Europium and argentum doped polycrystalline powders were obtained by the conventional solid state reaction; concentration of Eu and $\mathrm{Ag}$ was near $0.5 \mathrm{~mol} \%$ in all samples.

For the investigation the following techniques were used:

1. Time-resolved radioluminescence (RL). Excitation was induced by high-energy (4Mev) electron pulses of linear electron accelerator (LINAC) with $\sim 2.6 \mathrm{~ms}$ duration and $\sim 100$ Gy dose, time resolution $1 \mathrm{~ms}$. An optical system consisting of lenses, fiber optic bundels, grating monochromator and a photomultiplier tube was applied as light detecting system; a digital storage scope stored the signal as the function of time (Fig.1).

2. Thermoluminescence (TL). 3-D TL spectra measurements were carried out using spectrometer, described in [5]. TL glow curves dose - dependence measurments were performed as in [6].

\section{Results}

Radioluminescence and dosimetric properties in highdose rate region.

The study of time-resolved RL induced by high-energy $(4 \mathrm{MeV})$ accelerated electrons provides information 


\section{Ignatovych et al.: Radioluminescent and dosimetric properties of ...}

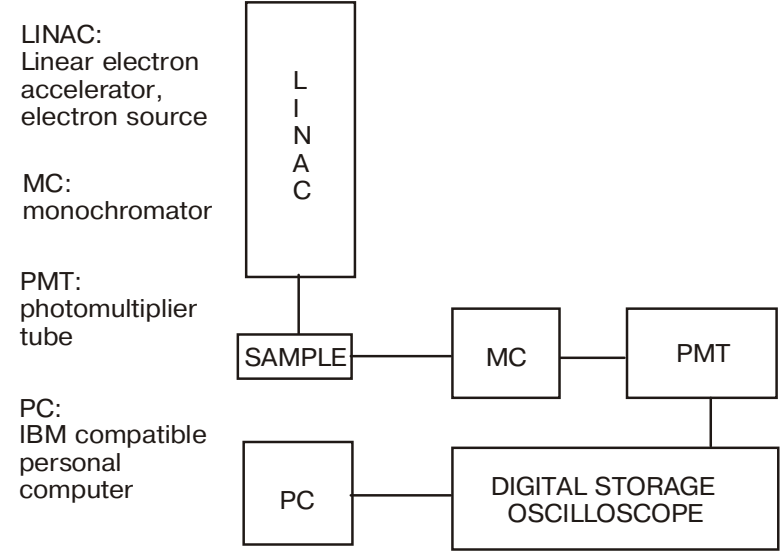

Fig. 1. Schematic drawing of experimental setup for time-resolved RL.

about the luminescent characteristics of investigated phosphors under high-energy and high - dose rate excitation. To our best knowledge, such measurements are carried out at first on these materials. Used facilities and approach elaborated and described in [7] permit measuring of series of RL decay curves at different electron doserates.

It is well demonstrated that the increasing electron intensity caused higher emitted light intensity. In order to get a relationship between the irradiation dose intensity and the total light output of the samples, we used $\mathrm{Al}_{2} \mathrm{O}_{3}: \mathrm{Mg}, \mathrm{Y}$ dosimeter chips for calibration. These TL chips were placed into the same sample holder as used for the tested phosphors, and the same nominal electron intensities were applied to them as to the samples. The evaluation of the TL detectors gave the dose values for the different electron intensities. As follows from Figs 2 to 4 good proportionality between the dose-rate and the light output of RL was observed for all tested phosphors.

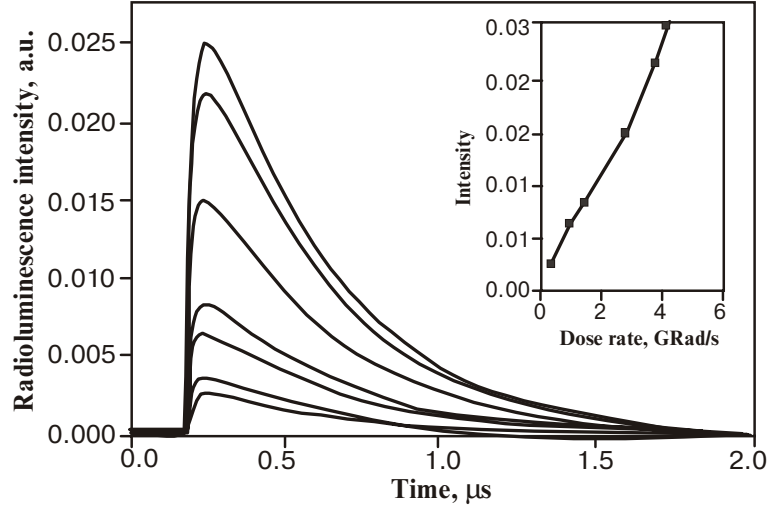

Fig. 3. Radioluminescence decay curves of ZnS.CdS:Ag irradiated with LINAC pulses of different dose-rate and the dose-rate dependence of the total emitted light measured at $530 \mathrm{~nm}$.

It was also revealed that the high-dose $\left(10^{4} \mathrm{~Gy}\right)$ LINAC irradiation did not caused the radiation damages of the luminescence centers and the emitting characteristics of the tested phosphors were preserved.

Thus, the obtained results permit us to consider investigated phosphors as promising dosimetric materials for extremely high-dose intensity region.

Thermoluminescence and dosimetric properties in lowdose rate region.

3-D TL spectra of $\mathrm{Sr}_{3}\left(\mathrm{PO}_{4}\right)_{2}: \mathrm{Eu}$ and $\mathrm{BaFCl}: \mathrm{Eu}$ are demonstrated in the Figs 5 and 6, respectivly. As seen in Fig. 5, the spectrum is characterized by two emission bands - in the blue (at $420 \mathrm{~nm}$ ) and red $(570 \mathrm{~nm})$ regions. Three distinct, well separated TL peaks are observed at $100^{\circ}, 140^{\circ}$ and $260^{\circ} \mathrm{C}$. For BaFCl:Eu sample the TL glow peaks are at $135^{\circ}, 270^{\circ}$ and $360^{\circ} \mathrm{C}$ (see Fig. 6). Such TL patterns suggest the presence of different luminescence centres and independent charge traps. Fig. 7 represents

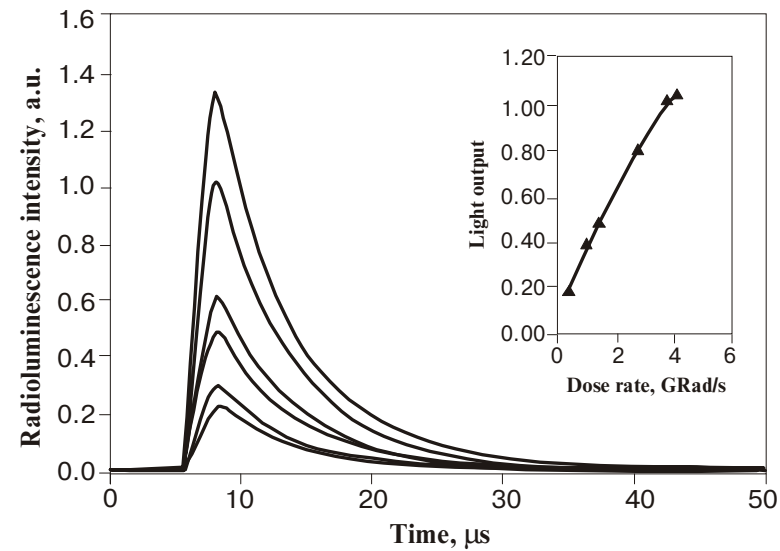

Fig. 2. Radioluminescence decay curves of BaFCl.Eu irradiated with LINAC pulses of different dose-rate and the dose-rate dependence of the total emitted light measured at $390 \mathrm{~nm}$.

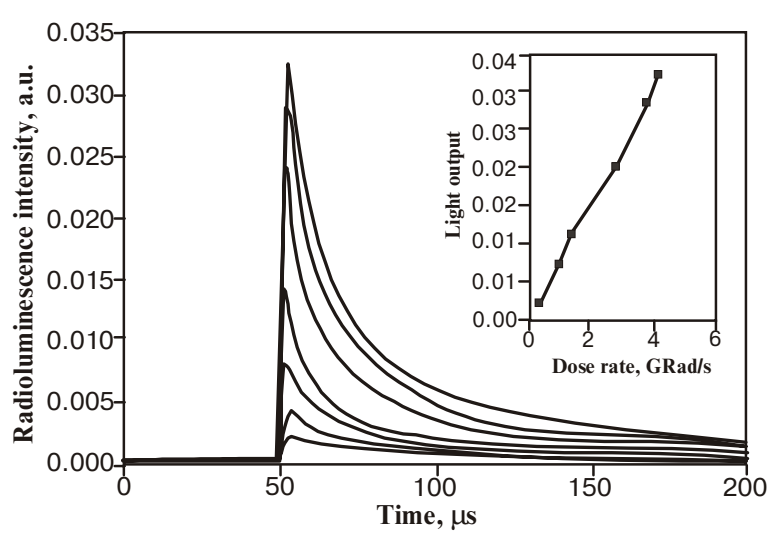

Fig. 4. Radioluminescence decay curves of $\mathrm{Y}_{2} \mathrm{O}_{3}: \mathrm{Eu}$ irradiated with LINAC pulses of different dose-rate and the dose-rate dependence of the total emitted light measured at $630 \mathrm{~nm}$. 


\section{Ignatovych et al.: Radioluminescent and dosimetric properties of ...}
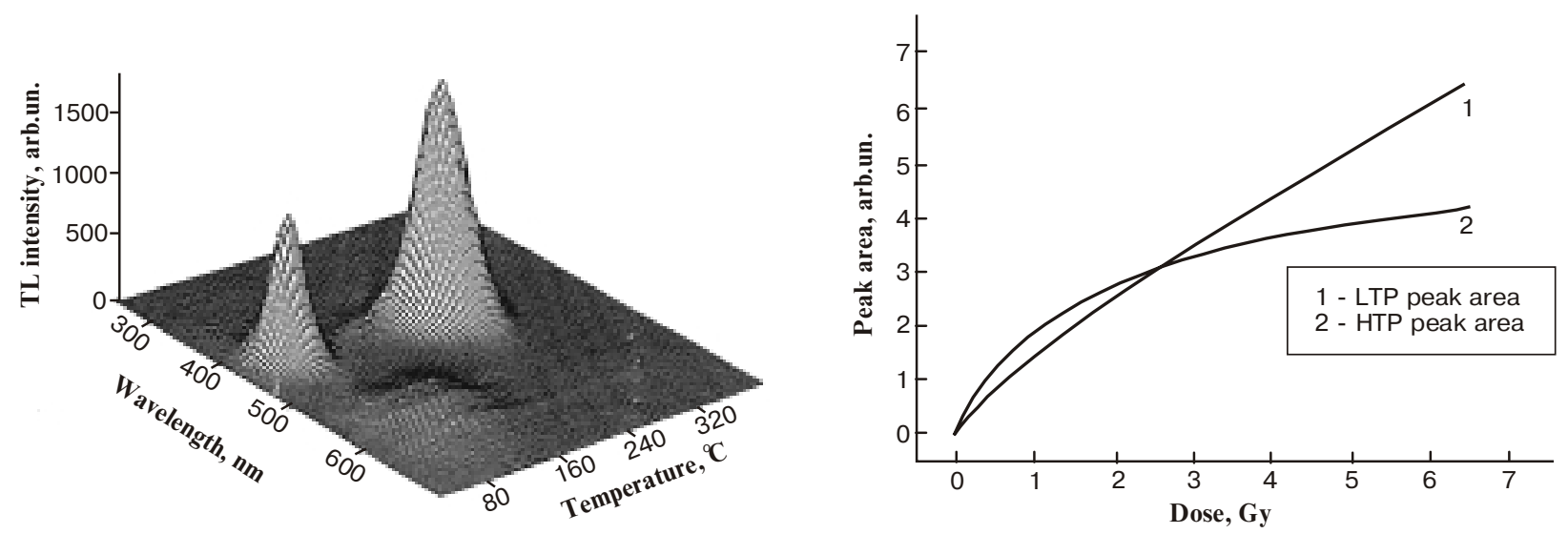

Fig. 5. 3-D TL emission of $\mathrm{Sr}_{3}\left(\mathrm{PO}_{4}\right)_{2}$ :Eu.

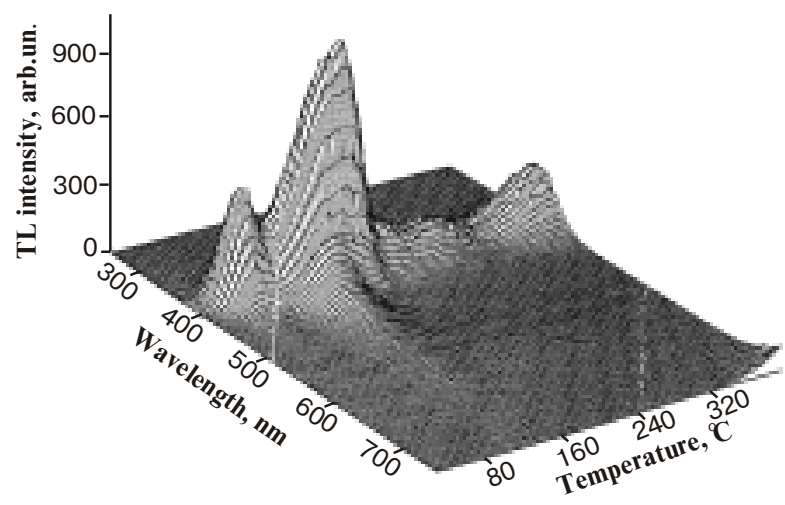

Fig. 8. TL dose dependence of the different TL peaks of $\mathrm{Sr}_{2}\left(\mathrm{PO}_{4}\right): \mathrm{Eu}$.

the dose dependence of glow peaks in the blue emission region for $\mathrm{Sr}_{3}\left(\mathrm{PO}_{4}\right)_{2}$ : $\mathrm{Eu}$ in the range of 0.4 to $1 \mathrm{~Gy}$. Further, as follows from Fig. 8, the low-temperature peak (LTP) exhibits linear dose dependence only below 2 Gy dose, while for the high-temperature peak(HTP) linear TL dose response is observed up to $6 \mathrm{~Gy}$ of beta-irradiation. For BaFCl:Eu phosphor good linearity of three TL glow peaks in the dose range 0.22-3.3 Gy has been observed. Such preliminary results allow to consider these two X-ray phosphors as a promissing TL dosimetric materials also for lower dose ranges.

In conclusion, performed RL characterization of tested phosphors allows to consider them as promising accidental dosimetric materials, while their TL properties proved be suitable for dosimetry in considerable lower dose range.

Fig. 6. 3-D TL emission of BaFCL:Eu.

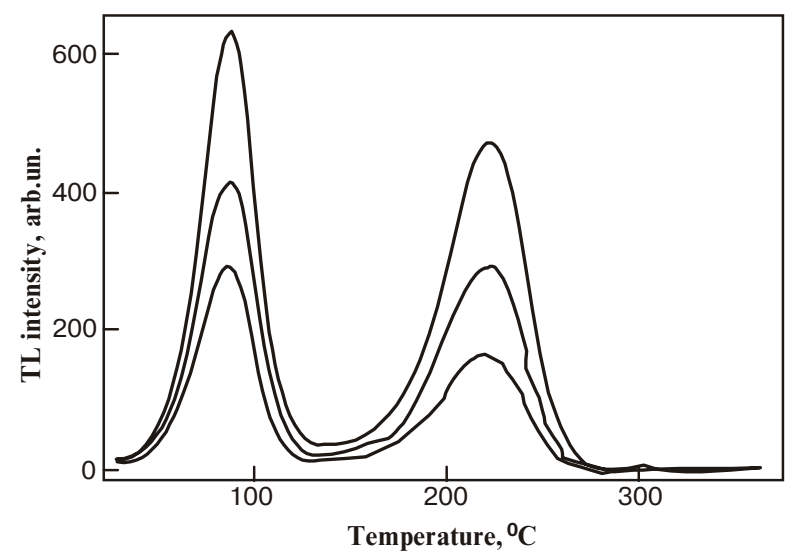

\section{Acknowledgements}

This study is part of an Agreement of scientific collaboration between the Academy of Sciences of Ukraine and Hungary and was alsofinancially supported in part by the Hungarian Science Foundation, No. OTKA T026070. Authors also highly appreciate the kind help of Dr. M. Osvay for performing the dose-rate evaluation by TL chips. Special thanks are addressed to the LPR-4 electron accelerator staff.

\section{References}

1. A.M. Gurvich, M.G. Myakhova, J. Rudiger, and V.P. Kavtorova, Phosphors for conventional and computed radiography // Nucl. Tracks Radiat. Meas, 21, pp. 29-33 (1993).

2. B. C. Grabmaier, W. Rossner, New scintillators for X-ray computed tomography // Nucl. Tracks Radiat. Meas, 21, pp. 43-45 (1993).

Fig. 7. Dependence of TL glow curves of $\mathrm{Sr}_{2}\left(\mathrm{PO}_{4}\right): \mathrm{Eu}$ on dose: $a-0.4 \mathrm{~Gy}, b-0.6 \mathrm{~Gy}, c-1.0 \mathrm{~Gy}$.

3. M. Ignatovych, A. Eremenko, V. Ogenko, A. Chuiko, Proc. of IRPA-9, 4, p.425, Vienna, (1996). 
M. Ignatovych et al.: Radioluminescent and dosimetric properties of ...

4. M. Ignatovych, A. Kelemen, A. Peto and V. Ogenko, Radiat. Prot. Dos. 84(1-4), pp. 185-188 (1999).

5. B.J.Luff, P. D.Townsend, High sensitivity thermoluminescence spectrometer // Measurement Science and Technology, 4(1), pp 65-71(1993).
6. N.Otvos, Basic thermoluminescence properties of $\mathrm{Sr}_{3}\left(\mathrm{PO}_{4}\right)_{2}: \mathrm{Eu} / /$ Radiat.Prot. Dos, 84(1-4), pp.135-134 (1999).

7. A.Peto, A.Kelemen, Radioluminescence of LiF:Mg,Ti induced by $4 \mathrm{MeV}$ electrons // Radiation Measurements, 24 (4), pp. 571-573 (1995). 